\title{
Lockwood on human identity and the primitive streak
}

\author{
A A Howsepian University of California, Fresno, California
}

\begin{abstract}
Michael Lockwood has recently concluded that it can be morally permissible to perform potentially damaging non-therapeutic experiments on live human (pre)embryos. The reasons he provides in support of this conclusion commit him inter alia to the following controversial theses: (I) an organism's potential for twinning bears critically on the identity conditions for that organism; and (ii) functionally intact mentalitymediating neurological structures play a critical role in establishing the identity conditions for human organisms. I argue that Lockwood has given us no good reason to endorse either of these theses and, hence, that he has given us no good reason to believe that it can be morally permissible to perform potentially damaging non-therapeutic experiments on live human (pre)embryos.
\end{abstract}

Michael Lockwood presents a novel variation on an increasingly popular family of arguments for the moral permissibility of performing potentially damaging non-therapeutic experiments on live human (pre)embryos. ${ }^{1}$ Kindred arguments which have appeared to some philosophers to lend support to this thesis have been proposed by Mary Warnock, ${ }^{2}$ Richard McCormick, ${ }^{3}$ and Peter van Inwagen. ${ }^{4}$ The issues at stake here are much too serious to be ignored. According to Lockwood, prior to differentiation the embryo could not possibly be a determinate human being. Why not? Because Lockwood possesses a "strong intuitive inclination" that you would not have existed if "those cells, in the embryo from which you came, that in fact gave rise to the fetus, had given rise, instead, to the placenta, and vice versa[.]" But this claim is, on the face of it, quite confused. Clearly, the placenta is a part of the fetus; it is, in virtue of both its functions and its chromosomal structure, one of the fetus's organs; specifically, its prenatal organ of (among other functions) respiration, nutrition, and excretion. Given that this is so, cells which give rise to a well-formed fetus could

\section{Key words}

Identity; embryology; twinning; human experimentation. not fail to give rise to its placenta. So, as it stands, Lockwood's initial attempt at arguing for the moral permissibility of non-therapeutic potentially damag- $\omega$ ing live human (pre)embryo experimentation fails. $\vec{\omega}$

Lockwood's point, though, does not rely upon the mereological status of the placenta. He later alludes 은 to his favoured argument by posing the following rhetorical question: "Would you have existed if the cells whose progeny in fact gave rise to your brain had given rise to your liver instead, and vice versa?" $\mathrm{He}$ imagines that the answer to this question is clearly, no. Is it? Not by my lights. In fact the answer $\vec{\ominus}$ appears clearly to be yes. Suppose that I contracteßa. disease in which all of the neurons in my centralo nervous system were gradually to die and, duriogs this same interval of time, were gradually to be replaced by new qualitatively identical neurons dif- -0 ferentiated from a focus of totipotent cells in the $\stackrel{\mathbb{\perp}}{\stackrel{\mathbb{Q}}{\alpha}}$ sinusoids of my liver which were subsequently trans- $\vec{F}$ ferred through my vascular system to the inside of 3 my skull and spinal column. Suppose that all of my? old central nervous system neurons were replaced by? new neurons in the course of this process of renewed neuronal differentiation. Would this organism with a new central nervous system be $m e$ ? It seems to meo quite clearly that it would.

We can, I think, even ignore Lockwood's appealô to neuronal "qualitative equivalence" as an unneces- $₹$ sary complication in this context. Even if the음 properly biointegrated Organism with the New $\triangle$ Brain (ONB) were, neurobiologically, very muchㅡㅡ. unlike the Organism with the Old Brain (OOB), stilln OOB would be (numerically) identical with ONB. The reason for this is that the cells that constitute ONB's brain are, like the cells that constitutedw OOB's brain, cells which were derived from me, and the brains so constituted are (by supposition)o properly functioning proper parts of a single unified, homeodynamic system - a system governed by a? single integrative principle of organisation - that comprises a single life, viz my life.

Lockwood may think that the above example is disanalogous to the scenario which he envisages. He尺्ष may think this because there does not appear to himo to be a determinate organism from which the cells which have undergone differentiation in the embryo 
could possibly have arisen, whereas there clearly is such a determinate organism in the case of renewed neuronal differentiation outlined above. But this, I take it, is precisely what is in question. Lockwood cannot simply presuppose that the pre-embryo is no determinate organism, for this is precisely what he alleges to show. Other related issues aside, the central charge against Lockwood, then, is one of question-begging.

\section{House illustrations}

It is curious that Lockwood's house illustrations ${ }^{5}$ are disanalogous to the pre-embryo situation in precisely the way in which they should not be were they to be illuminating. In the pre-embryo case, the "materials" for organogenesis are all derived, most proximately, from a unified biological homeodynamic system, namely, the pre-embryo. All of the totipotent cells in question, therefore, that are involved in embryonic tissue differentiation stand in the proper mereological relation to the pre-embryo of which they were proper parts. (I have defended this view at length elsewhere) ${ }^{6}$ I fail to see how, in Lockwood's case, it is at all relevant to metaphysical identity considerations that a certain subset of pre-embryonic cells may, in one circumstance, have given rise to the embryo's brain while, in another circumstance, these same cells may have given rise instead to its liver or lungs and vice versa. One could, of course, simply presuppose, as Lockwood appears to do, that the identities of undifferentiated pre-embryos are, in fact, indeterminate. If this were in fact the case, then it is at least plausible to hold that tissue differentiation and organogenesis do, as Lockwood claims, provide proper organismic identity conditions. But, as noted, to presuppose this is to presuppose what I had thought Lockwood was attempting to demonstrate.

It is, in fact, quite unclear how Lockwood's house analogies are supposed to be understood. The attempted analogies are not at all illuminating, partly in virtue of the fact that the identity conditions for houses and other putative inanimate composite objects (if there are any such identity conditions or any such objects) are notoriously obscure. Perhaps the reason why Ship of Theseus puzzles are thought to be so refractory to resolution is that, as van Inwagen ${ }^{4}$ has concluded, there are no such things as ships (or houses or, for that matter, any composite inanimate things). There can be little doubt, though, that there are such things as living organisms. So, attempts to illuminate the identity conditions for organisms, as Lockwood has done, by using analogies involving inanimate "objects" such as houses are, as I see it, methodologically misshapen.

In spite of the fact that Lockwood claims that "the possibility of twinning need not be brought into the argument at all[,]" he goes on to discuss, without significant critical comment, arguments for the moral permissibility of performing potentially damaging experiments on human (pre)embryos which rely upon twinning considerations. He states that "it would seem to follow that, as long as there was a possibility of such twinning occurring, the identity of the human being(s), if any, to which your mother's pregnancy was going to give rise was not yet determined. And from that in turn it would seem to follow that, as long as the possibility of twinning existed, you did not exist." This kind of argument, he states, "appears to provide a philosophical rationale for the Warnock Committee's decision to recommend that experimentation on live human embryos of less than fourteen days be permitted in law." 1 This appearance is illusory. If it were the case that the multiple isogenic progeny of an organism are, of biological necessity, derivable only from biocellular sources the organismic identities of which are indeterminate, then it follows that the identities of organisms which can reproduce either by cloning or by parthenogenesis are themselves indeterminate. Several species of organisms reproduce by parthenogenesis, including several species of insects, reptiles, amphibians and birds. Worse yet, there is no in principle biological reason for thinking that any given multicellular organism - including human organisms - could not be cloned in the laboratory. But if this is so, it follows from the above adumbrated twinning argument that the identity of no multicellulare organism(s) have yet been determined. But this is? absurd. (An argument along similar lines, and in more detail, can be found elsewhere. $)^{6}$

It appears to be devastating to the viability of the aforementioned twinning argument, therefore, simply to point out that there is a biological possibility that a twin of Lockwood himself (ie, an organism which is isogenic with Lockwood) is, in fact, derivable in principle from one of Lockwood's nucleated somatic cells. But if this is so, then given the cogency of the above twinning argument, the identity of Lockwood himself has not yet been (and in fact never will be) determined.

\section{Primitive streak}

We do not, therefore, (contra Warnock) possess any good reason to think that "before fourteen days, the human embryo hasn't yet decided how many people it's going to be"7 in virtue of the failure by reductio of the above adumbrated twinning argument. Apparently, twinning can occur "after the formation, at around fourteen days, of the primitive streak, the precursor of the spinal cord". ${ }^{1}$ Neither has Lockwood given us any good reason to believe that arguments based on differentiation fare any better in this regard. At least the argument presented by Lockwood appears clearly to beg the question. It appears, then, that the passage into law of the Human Fertilisation and Embryology Act of 1991 in England - an Act the conceptual structure of which 
appears to have been based upon some of the considerations outlined above (although its primary motivations remain obscure) - might have been motivated by a family of egregious, and arguably pernicious, conceptual mistakes.

Apparently, though, this can all be side-stepped by Lockwood: he appears to believe that he need not rely on any of the aforementioned arguments in order to support his conclusion regarding the moral permissibility of performing potentially damaging experiments on human (pre)embryos, for he believes that "the only part of the body on which a human being's identity really depends is the brain; and more specifically that part or aspect of the brain which directly supports mentality". He goes so far as to say: "Just as we now think of a human life as having ended when that part or aspect of the brain in which thoughts and feelings occur has been destroyed, so it seems to me that we ought, in consistency, to think of a human life as not having begun when the relevant part or aspect of the brain has yet to come into existence". 1

Just who is being referred to here as the "we" who now think of a human life as having ended merely when a certain proper part of the brain has been "destroyed"? Lockwood appears to be out of touch with current opinion concerning conceptions of human death. There is no indication of which I am aware that the informed majority's view on this matter is anything other than the standard view, viz that a developmentally mature human organism is dead if and only if its whole brain is dead. ${ }^{8}$ Lockwood's view is certainly part of only a very small, albeit growing, minority's view of human death - a view which, as I see it, has very little to recommend it. ${ }^{9}$

One principal motivation for rejecting such higher-brain-oriented definitions of death (HBODsD) is that this family of definitions appears to commit one to the following implausible theses: First, HBODsD appear currently to presuppose that "destroyed" biological processes (for example, the "destruction" of those neurobiological processes which mediate consciousness in humans) which we do not currently possess the technology to reverse are irreversible. (I take it that this is what is meant by the processes' being destroyed.) But certainly a process's being such that it has not been reversed using current technology is not thereby, merely in virtue of this, a process which is irreversible.

\section{Promises of neuroscience}

It seems that HBODsD adherents tend not to place very much confidence in the promises of neuroscience. There is, of course, no in principle reason to think that central nervous system neurons - like some peripheral nervous system neurons - could not, if treated properly, regenerate and reorganise themselves in such a manner that a previously chronically unconscious human organism regained conscious $-\stackrel{\mathbb{D}}{\stackrel{2}{2}}$ ness. It is well known that analogous processes ofm generation and organisation take place in pre-born human organisms: human fetal development begins ? in total phenomenal darkness (ie, in complete uncon- $\overrightarrow{\vec{F}}$ sciousness); consciousness arrives on the scene only? when the fetal brain achieves the requisite level of

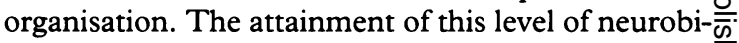
ological organisation is driven, in large part, by $a \widehat{\Phi}$ genetic program which operates within a field of $\varrho$ developing neurons. There is, therefore, absolutelyc no reason to believe that the very same genes which $\overrightarrow{0}$ earlier governed the initial organisation of thosedeveloping central nervous system (CNS) structures ${ }_{\sigma}$ which mediated consciousness in the human fetus and which are, in the ordinary course of events, $\mathbb{D}$ turned off in adult humans, could not again, at some $e_{\tilde{C}}^{N}$ later time, be turned on. Likewise, there is absolutely no reason to believe that the cellular environment in $\omega_{\infty}$ which the proper neuronal connections were earliero established in the CNS could not again be made hos-pitable to the development of that degree of neuronal 7 regeneration and reorganisation which would again음 permit the emergence of human consciousness.

\section{Metaphysical view}

Of course, Lockwood might agree that the afo mentioned neuroscientific advances are within the realm of physical possibility. He might insist that view says nothing about what the practical limits of neuroscience are, but rather that he is simplyळ advancing a metaphysical view concerning the identity of biological organisms.

Suppose that the neural structures which $\frac{3}{5}$ mediated Jones's conscious life were "destroyed" in just that manner in which Lockwood envisions Further suppose that a brilliant neuroscientist were able to to rewire Jones's brain in a manner that is exactly similar to how his brain was wired prior to the aforementioned "destruction". (Again, given all that we know about biology, this is certainly not outside the realm of physical possibility.) Would not thiso organism with the re-wired nervous system be Jones? No one, including Lockwood, has given us any goodo reason to believe that it would not; and there is at least one powerful reason for thinking that this. organism would be Jones, namely, that the Jones 0 with the lesioned brain and the re-wired Jones are స్ట the same living organism.

It would be a mistake to counter by claiming, in the following manner, that the above argument $\frac{\mathbb{\Phi}}{c}$ proves too much: certainly it is physically possible, ? by way of intensive biotechnological manipulations, 7 to re-wire and thereby revive some bodies whicho even whole-brain death adherents would consider to be dead. Thus, given the cogency of the above $\overrightarrow{\mathbb{Q}}$ argument, some humans who are uncontroversiallyo judged to be dead even by whole-brain death criteria would, in fact, not be dead. 
But this counter-argument fails for the following reason: there are, strictly speaking, no such things as dead human bodies. What are ordinarily called "dead human bodies" are nothing more than heaps of physical simples (for example, heaps of elementary particles) arranged human-body-wise. Such physical simples are not, merely in virtue of being arranged in the shape of a (live) human body thereby unified into any one single thing. In constrast, the physical simples which make up what might be called a "nonwhole-brain-dead dead human body" by HBDOD standards clearly make up what is a single unified thing. It just so happens to be a single unified thing that, at present anyway, happens not to be conscious.

A A Howsepian, MD, MA(Philosophy), is Resident in Psychiatry at the University of Califormia, San Francisco-Fresno Central San Foaquin Valley Medical Education Program and is studying for a PhD at the University of Notre Dame, Notre Dame, Indiana.

\section{References}

1 Lockwood M. Human identity and the primitive streak. Hastings Center Report 1995; 25,1: 45.

2 Department of Health and Social Security. Report of the Committee of Inquiry into Human Fertilisation and Embryology. London: HMSO, 1984: Cmnd 9314: para 11.22 .
3 McCormick RA. Who or what is the preembryo? Kennedy Institute of Ethics fournal 1991; 1: 1-15.

4 van Inwagen P. Material beings. Ithaca: Cornell University Press, 1990.

5 These analogies are presented in the form of questions: (a) "By analogy, would the house in which you now live have existed had there been built, on the site of your house, a qualitatively identical one made out of different bricks, different planks of wood, and so forth?" (b) "Analogously, would the house in which you now live have existed if a qualitatively identical one had been built, on the same site, out of the same bricks, wood, and so on, but, in completely different places?"

6 Howsepian AA. Who or what are we? Review of Metaphysics 1992; 45: 483-502.

7 Stated by Mary Warnock in a television interview and quoted in Lockwood, reference 1.

8 See, for example, the President's Commission for the Study of Ethical Problems in Medicine and Biomedical and Behavioral Research. Defining death: medical, legal and ethical issues in the definition of death. Washington, DC: US Government Printing Office, 1981.

9 This minority includes, among others, Veatch RM. The impending collapse of the whole-brain definition of death. Hastings Center Report 1993; 23,4:18-24, and Lizza JP. Persons and death: what's metaphysically wrong with our current statutory definition of death?" Fournal of Medicine and Philosophy 1993; 18: 351-74.

\section{News and notes}

\section{Ethical Codes in Medicine}

The German Akademie fur Ethik in der Medizin is holding a conference entitled Ethical Codes in Medicine, 1947-1997, Origins - Impact - Implications, in Freiburg from October 11-15 1997.

The conference will examine the origins and impact of certain codes; how they can and do function as instruments; what the code-of-ethics concept has and has not achieved to date, and the need for conceiving new codes for particular medical fields.

For further information contact: The Freiburg Project, Zentrum fur Ethik und Recht in der Medizin, im Universitatsklinikum, Albert-Ludwig-Universitat, Eisasser Strasse 2m/Haus 1a, D-79110 Freiburg, Germany. Tel: ++49-(0)761-270-7265; fax: ++49(0)761-270-7268; e-mail: fproject@sunl.ukl.uni. freiburg.de 